BMJ Open Diabetes Research \& Care

\title{
Neighborhood walkability and risk of gestational diabetes
}

\author{
Simone Kew, ${ }^{1}$ Chang Ye, ${ }^{1}$ Sadia Mehmood, ${ }^{1}$ Anthony J Hanley (D) , ${ }^{1,2}$ \\ Mathew Sermer, ${ }^{3}$ Bernard Zinman, ${ }^{1,4,5}$ Ravi Retnakaran (1) 1,4,5
}

To cite: Kew S, Ye C, Mehmood S, et al. Neighborhood walkability and risk of gestational diabetes. BMJ Open Diab Res Care 2020;8:e000938. doi:10.1136/ bmjdrc-2019-000938

Received 26 September 2019 Revised 10 December 2019 Accepted 25 December 2019

Check for updates

(C) Author(s) (or their employer(s)) 2020. Re-use permitted under CC BY-NC. No commercial re-use. See rights and permissions. Published by BMJ.

${ }^{1}$ Leadership Sinai Centre for Diabetes, Mount Sinai Hospital, Toronto, Ontario, Canada ${ }^{2}$ Nutritional Sciences, University of Toronto, Toronto, Ontario, Canada

${ }^{3}$ Obstetrics and Gynecology, Mount Sinai Hospital, Toronto, Ontario, Canada

${ }^{4}$ Division of Endocrinology and Metabolism, University of Toronto, Toronto, Ontario, Canada

${ }^{5}$ Lunenfeld-Tanenbaum Research Institute, Toronto, Ontario, Canada

Correspondence to Dr Ravi Retnakaran; Ravi.Retnakaran@ sinaihealthsystem.ca

\section{ABSTRACT}

Objective Higher neighborhood walkability has been associated with a lower risk of type 2 diabetes mellitus (T2DM) by promoting greater physical activity (thereby reducing weight and lowering insulin resistance). However, it is not known if walkability may similarly reduce maternal risk of gestational diabetes mellitus (GDM), which arises in the setting of the severe physiologic insulin resistance of pregnancy. Indeed, the insulin resistance of pregnancy is primarily driven by placental hormones and not maternal weight gain. Thus, we sought to evaluate the impact of neighborhood walkability on maternal risk of GDM and the pathophysiologic determinants thereof (insulin sensitivity and pancreatic beta-cell function).

Methods In this study, 1318 women reported their pregravid physical activity (Baecke questionnaire) while undergoing an oral glucose tolerance test (OGTT) at mean 29.3 weeks' gestation. The OGTT identified 290 women with GDM and enabled assessment of insulin sensitivity and beta-cell function. Based on their residential Walk Score, the women were stratified into the following four established categories of neighborhood walkability: car dependent $(n=328)$, somewhat walkable $(n=315)$, very walkable $(n=406)$, and walker's paradise $(n=269)$.

Results There was a progressive increase in pregravid total physical activity ( $p=0.002)$, non-sport leisure-time activity $(p=0.009)$ and sport activity $(p=0.01)$ across the walkability groups (from car dependent to somewhat walkable to very walkable to walker's paradise), coupled with a concomitant decline in pre-pregnancy body mass index ( $p=0.007)$. However, in pregnancy, the groups did not differ in gestational weight gain $(p=0.80)$. Moreover, the walkability groups also did not differ in mean adjusted insulin sensitivity, beta-cell function, or glycemia on the antepartum OGTT. On logistic regression analysis, Walk Score did not predict GDM (OR=1.001, $95 \% \mathrm{Cl} 0.995$ to 1.007).

Conclusion Neighborhood walkability is not a significant determinant of maternal risk of GDM. Thus, in contrast to T2DM, the effect of neighborhood design on incidence of GDM will be comparatively modest.

\section{INTRODUCTION}

Type 2 diabetes mellitus (T2DM) is a global epidemic affecting more than 425 million people worldwide, as per latest estimates from the International Diabetes Federation (IDF). ${ }^{1}$ As a health problem of this magnitude arguably requires a societal solution(s), there is growing interest in urban planning as

\section{Significance of this study}

What is already known about this subject?

- Higher neighborhood walkability has been associated with a lower risk of type 2 diabetes but it is not known if it may similarly reduce maternal risk of gestational diabetes, which has pathophysiologic similarities to type 2 diabetes but also salient differences that may relate to the extent to which enhanced walkability could be beneficial.

What are the new findings?

- Higher neighborhood walkability is associated with greater pregravid physical activity and lower BMI.

- However, when the same women become pregnant, neighborhood walkability does not relate to gestational weight gain, insulin sensitivity, beta-cell function or glycemia.

- Neighborhood walkability is not associated with maternal risk of gestational diabetes

How might these results change the focus of research or clinical practice?

- While neighborhood design may reduce the risk of type 2 diabetes, any effect that it might have on the incidence of gestational diabetes will be comparatively modest, reflecting the intrinsic physiologic differences between the gravid and non-gravid states.

a means of promoting healthy lifestyle practices and thereby addressing this epidemic. ${ }^{2}$ In particular, higher neighborhood walkability has been associated with a lower prevalence of overweight/obesity and lower risk of diabetes. ${ }^{2-5}$ The presumed mechanism underlying these associations is that neighborhood walkability encourages a more active lifestyle that reduces the likelihood of excessive weight gain over time and thereby limits obesity-associated insulin resistance that would otherwise contribute to the development of T2DM in those individuals in whom pancreatic beta-cell compensation would be insufficient to fully mitigate such a challenge.

In parallel with the global burden of T2DM, there is also a rising incidence of hyperglycemia in pregnancy. Indeed, according to the IDF, the proportion of pregnancies affected 
by maternal hyperglycemia worldwide increased from one in seven in 2011 to one in six pregnancies in $2015 .{ }^{1}$ Moreover, this rising prevalence potentially may portend a transgenerational future burden of disease in those individuals in whom intrauterine exposure to maternal hyperglycemia may have adverse consequences for developmental programming of metabolic pathways (as per the Developmental Origins of Health and Disease paradigm). ${ }^{6}$ Thus, if enhanced neighborhood walkability could lower the risk of gestational diabetes mellitus (GDM), then the beneficial effects could be relevant to both mother and child, and thereby provide a transgenerational approach to the diabetes epidemic. However, the impact of neighborhood walkability on risk of GDM is not known.

Although both GDM and T2DM are characterized by the same general pathophysiologic basis (insufficient beta-cell compensation for ambient insulin resistance), ${ }^{7}$ there are important differences in their respective settings that may relate to the extent to which neighborhood walkability could be beneficial. Specifically, in contrast to the non-gravid state, pregnancy is a discrete 9-month interval during which some degree of weight gain is both physiologic and necessary. ${ }^{8}$ Second, the progressive insulin resistance that characterizes the second half of pregnancy is physiologic and is primarily mediated by placental hormones (ie, rather than weight gain as in the non-gravid state). Third, compared with the impact of weight gain on insulin sensitivity outside of pregnancy, the normal physiologic insulin resistance of the latter half of gestation is of such a profound magnitude that its capacity for modification by urban design potentially might be limited. Thus, it is quite unclear whether enhanced walkability could have a beneficial effect on GDM, in the way that it does for T2DM. In this context, our objective in this study was to evaluate the impact of neighborhood walkability on maternal risk of GDM and the pathophysiologic determinants thereof (insulin sensitivity/resistance and beta-cell function).

\section{METHODS}

The study population consisted of pregnant women in Toronto, Canada, who were recruited to undergo metabolic characterization at the time of antepartum screening for GDM. The study protocol has been previously described in detail. ${ }^{9}$ At our institution, all pregnant women undergo universal GDM screening at 24-28 weeks' gestation with a $50 \mathrm{~g}$ glucose challenge test (GCT), which is then followed by a diagnostic oral glucose tolerance test (OGTT) if the GCT result is abnormal (blood glucose $\geq 7.8 \mathrm{mmol} / \mathrm{L}$ at 1 hour after challenge). For this study, healthy pregnant women are recruited either prior to or just after their GCT. Regardless of the GCT result (ie, even if normal), all study participants undergo a 3-hour $100 \mathrm{~g}$ OGTT for determination of GDM status. As previously described, ${ }^{9}$ the recruitment of women after an abnormal GCT serves to enrich the study population for those with GDM. The current analysis was performed in women living in Toronto for whom complete home address information was provided $(\mathrm{n}=1318)$.

\section{Assessment of study participants}

On the morning of the 3-hour $100 \mathrm{~g}$ OGTT in pregnancy, data regarding medical, obstetrical, and family history were collected by interviewer-administered questionnaire. Pregravid physical activity in the year before pregnancy was assessed using the Baecke questionnaire, an established instrument that has been extensively validated in several populations, including women of childbearing age. ${ }^{10} 11$ The Baecke questionnaire measures total physical activity and its three component domains: (1) occupation-associated activity (work index), (2) sportrelated physical activity (sport index), and (3) non-sport leisure-time activity (leisure-time index). The work index quantifies the exertion related to occupational activities, such as sitting, standing, lifting, and walking, as well as associated effects on the individual (eg, fatigue, perspiration). The sport index characterizes vigorous/sports activity with respect to intensity (using the compendium of physical activities), ${ }^{12}$ duration, and frequency. The leisure-time index quantifies exertion associated with non-sport recreational activities (eg, walking and television viewing). Participants completed the Baecke questionnaire during their OGTT (ie, prior to knowledge of GDM status). GDM was diagnosed according to National Diabetes Data Group (NDDG) criteria $^{13}$ which require at least two of the following on the OGTT: fasting blood glucose $\geq 5.8 \mathrm{mmol} / \mathrm{L}, 1$-hour blood glucose $\geq 10.6 \mathrm{mmol} / \mathrm{L}$, 2-hour blood glucose $\geq 9.2 \mathrm{mmol} / \mathrm{L}$, or 3-hour blood glucose $\geq 8.1 \mathrm{mmol} / \mathrm{L}$.

\section{Metabolic characterization on OGTT}

All OGTTs were performed in the morning after overnight fast, with venous blood samples drawn for the measurement of glucose and specific insulin at fasting and at 30,60, 120 and $180 \mathrm{~min}$ following the ingestion of the $100 \mathrm{~g}$ glucose load. Specific insulin was measured with the Roche Elecsys 1010 immunoassay analyzer and electrochemiluminescence immunoassay kit (Roche Diagnostics, Laval, Canada). Area-under-the-glucose curve on the OGTT $\left(\mathrm{AUC}_{\text {glucose }}\right)$ was calculated by trapezoidal rule. Insulin sensitivity was measured with the Matsuda index, an established measure of whole-body insulin sensitivity that has been validated against the euglycemichyperinsulinemic clamp. ${ }^{14}$ Hepatic insulin resistance was assessed with the homeostasis model assessment of insulin resistance (HOMA-IR). ${ }^{15}$ Beta-cell function was assessed with the insulin secretion-sensitivity index-2 (ISSI-2), an OGTT-derived measure that is analogous to the disposition index from the intravenous glucose tolerance test, against which it has been validated. ${ }^{16}{ }^{17}$ ISSI-2 is defined as the product of (1) insulin secretion measured by the ratio of the area-under-the-insulin curve to $\mathrm{AUC}_{\mathrm{glu}}$ and (2) insulin sensitivity measured by the Matsuda index. The insulinogenic index divided by HOMA-IR 
(insulinogenic index/HOMA-IR) provided a second established measure of beta-cell function (with insulinogenic index defined as the ratio of the incremental change in insulin during the first $30 \mathrm{~min}$ of the OGTT to the incremental change in glucose over the same time period) ${ }^{9}$

\section{Determination of neighborhood walkability}

The walkability of each woman's residential neighborhood was assessed using Walk Score, which is an established index that reflects the walkability of an address using an algorithm that considers its distance to 13 amenities (grocery stores, coffee shops, restaurants, bars, movie theaters, schools, parks, libraries, bookstores, fitness centers, drugstores, hardware stores, clothing/ music stores) and aspects of pedestrian friendliness (such as population density, block length, and intersection density). Walk Score is a validated measure ${ }^{18-20}$ that has been associated with cardiometabolic risk factors such as physical activity, weight and blood pressure, ${ }^{21-24}$ including previous studies in Toronto. ${ }^{21}{ }^{22}$ It yields a numerical score that ranges from 0 to 100 , from which categories of walkability have been previously established, ${ }^{21} 2324$ ranging from 'car-dependent' (Walk Score $<50$ ) to 'somewhat walkable' (Walk Score 50-69 inclusive) to 'very walkable' (Walk Score 70-89 inclusive) to 'walker's paradise' (Walk Score 90-100 inclusive). We determined the walkability for each participant's home address using the publicly available Walk Score interface (https://www.walkscore.com/).

\section{Statistical analyses}

All analyses were conducted using SAS V.9.2 (SAS Institute). Walk Score was analyzed as both a continuous and categorical variable. Based on their home address Walk Score, the study participants were first stratified into four previously established Walk Score categories reflecting neighborhood walkability: (1) car-dependent (Walk Score $<50$ ), (2) somewhat walkable (Walk Score 50-69 inclusive), (3) very walkable (Walk Score 70-89 inclusive) and (4) walker's paradise (Walk Score 90-100 inclusive). Continuous variables were tested for normality of distribution, and natural log transformations of skewed variables were used, where necessary, in subsequent analyses. The demographic and clinical characteristics of the four groups were compared by analysis of variance (ANOVA) for continuous variables, or either $\chi^{2}$ or Fisher's exact test for categorical variables. Mean values of non-sport leisuretime index, vigorous/sport index, work index, total physical activity score, pre-pregnancy body mass index (BMI), and weight gain in pregnancy were compared across the four Walk Score groups by ANOVA. In addition, pairwise comparisons with Bonferroni adjustment were performed to determine if significant differences existed between any pairs of groups.

Spearman correlation analysis was performed to evaluate univariate correlations between continuous Walk Score and (1) pregravid features (physical activity, BMI), and (2) metabolic function in pregnancy, respectively. Multiple linear regression analyses were performed to compare the four Walk Score groups with respect to mean adjusted values for the following metabolic outcomes in pregnancy: insulin sensitivity/resistance (Matsuda index, HOMA-IR), beta-cell function (ISSI-2, insulinogenic index/HOMA-IR), and glycemia (fasting glucose, $\mathrm{AUC}_{\text {glucose }}$ on the OGTT). These comparisons were performed after adjustment for age, ethnicity, family history of diabetes, parity, pre-pregnancy BMI, weight gain in pregnancy up to the OGTT, and weeks' gestation at the OGTT. For each of these six metabolic outcomes, we conducted sensitivity analyses (1) by further adjusting for fetal sex and (2) by replacing Walk Score groups with continuous Walk Score. In addition, we conducted sensitivity analyses of these comparisons of mean adjusted metabolic outcomes in (1) women of white ethnicity, (2) nulliparous women, and (3) women who had no family history of diabetes (ie, reflecting variables that differed between the four Walk Score groups). Logistic regression analysis was performed to evaluate whether continuous Walk Score was an independent predictor of GDM after adjustment for the same covariates as in the multiple linear regression analyses.

\section{RESULTS}

\section{Comparison of Walk Score groups}

The study population of 1318 women underwent the antepartum OGTT at mean 29.3 weeks' gestation, which identified 290 women as having GDM. Table 1 shows demographic and clinical characteristics of the study population stratified into four Walk Score groups reflecting different degrees of neighborhood walkability: (1) car dependent $(\mathrm{n}=328),(2)$ somewhat walkable $(n=315)$, (3) very walkable $(n=406)$, and (4) walker's paradise $(n=269)$. These groups did not differ with respect to age or smoking. The lower walkability groups had a higher proportion of women of white ethnicity $(p=0.0006)$ and higher parity $(p=0.0004)$, coupled with a slightly greater prevalence of family history of diabetes $(\mathrm{p}=0.02)$.

Figure 1 shows the comparisons of the Walk Score groups with respect to physical activity in the year prior to the pregnancy, pre-pregnancy BMI, and gestational weight gain up to the OGTT. As shown in figure 1A, mean non-sport leisure-time activity progressively increased across the four groups as the neighborhoods became more walkable $(p=0.009)$. A similar but milder gradient was seen for the vigorous/sport index (figure $1 \mathrm{~B}, \mathrm{p}=0.01$ ). As anticipated, there was no difference across the groups in work index (figure 1C, $\mathrm{p}=0.49$ ), Overall, there was a clear stepwise increase in pregravid total physical activity from the car-dependent group to somewhat walkable to very walkable to walker's paradise (figure $1 \mathrm{D}, \mathrm{p}=0.002$ ) . This pattern translated to an analogous decrease in prepregnancy BMI from the less walkable to more walkable groups (figure $1 \mathrm{E}, \mathrm{p}=0.007$ ), with mean pre-pregnancy 
Table 1 Characteristics of study population, stratified according to Walk Score category as follows: (1) car dependent, (2) somewhat walkable, (3) very walkable, and (4) walker's paradise

\begin{tabular}{|c|c|c|c|c|c|}
\hline & Car dependent & Somewhat walkable & Very walkable & Walker's paradise & \\
\hline & (Walk Score <50) & (Walk Score 50-69) & (Walk Score 70-89) & (Walk Score 90-100) & \\
\hline & $(n=328)$ & $(n=315)$ & $(n=406)$ & $(n=269)$ & $P$ value \\
\hline Walk Score mean (SD) & $31.4 \pm 13.1$ & $60.0 \pm 5.9$ & $80.6 \pm 5.7$ & $94.5 \pm 3.0$ & \\
\hline Walk Score median (IQR) & $33(22-43)$ & $60(55-65)$ & $81(76-86)$ & $94(92-97)$ & \\
\hline \multicolumn{6}{|l|}{ Characteristics } \\
\hline Age (years) & $34 \pm 4$ & $34 \pm 5$ & $34 \pm 5$ & $34 \pm 4$ & 0.43 \\
\hline Ethnicity & & & & & 0.0006 \\
\hline White, n (\%) & $236(72.0)$ & $224(71.1)$ & $264(65.0)$ & $149(55.4)$ & \\
\hline Asian, n (\%) & $41(12.5)$ & $40(12.7)$ & $61(15.0)$ & $58(21.6)$ & \\
\hline Other, n (\%) & $51(15.5)$ & $51(16.2)$ & $81(20.0)$ & $62(23.0)$ & \\
\hline Family history of DM, n (\%) & $221(69.9)$ & $198(65.4)$ & $232(59.2)$ & $156(61.2)$ & 0.02 \\
\hline Smoking & & & & & 0.86 \\
\hline Never, n (\%) & $224(68.3)$ & $226(72.0)$ & $283(69.7)$ & $190(70.6)$ & \\
\hline Remote, n (\%) & $96(29.3)$ & $84(26.7)$ & $112(27.6)$ & $73(27.2)$ & \\
\hline Current, n (\%) & $8(2.4)$ & $4(1.3)$ & $11(2.7)$ & $6(2.2)$ & \\
\hline Parity & & & & & 0.0004 \\
\hline Nulliparous, n (\%) & $154(47.0)$ & $151(48.0)$ & $231(56.9)$ & $172(63.9)$ & \\
\hline $1, \mathrm{n}(\%)$ & $128(39.0)$ & $121(38.7)$ & $137(33.7)$ & $72(26.8)$ & \\
\hline$>1, \mathrm{n}(\%)$ & $46(14.0)$ & $42(13.3)$ & $38(9.4)$ & $25(9.3)$ & \\
\hline Previous GDM, n (\%) & $18(5.7)$ & $23(7.5)$ & $29(7.5)$ & $7(2.9)$ & 0.07 \\
\hline Pre-pregnancy BMI class & & & & & 0.14 \\
\hline Obese, n (\%) & $61(18.8)$ & $55(17.9)$ & $52(13.4)$ & $36(13.6)$ & \\
\hline Overweight, n (\%) & $77(23.8)$ & $74(24.0)$ & $94(24.2)$ & $51(19.3)$ & \\
\hline Normal, n (\%) & $186(57.4)$ & $179(58.1)$ & $242(62.4)$ & $177(67.1)$ & \\
\hline Gestational hypertension & $10(3.1)$ & $12(3.8)$ & $11(2.7)$ & $2(0.7)$ & 0.09 \\
\hline
\end{tabular}

Bold indicates $\mathrm{p} \leq 0.001$.

Age is presented as mean \pm SD. Pre-pregnancy BMI classes were defined as follows: (1) obese: $\mathrm{BMI} \geq 30 \mathrm{~kg} / \mathrm{m}^{2}$; (2) overweight: $25 \leq \mathrm{BMl}<30 \mathrm{~kg} / \mathrm{m}^{2}$; and (3) normal: $\mathrm{BMl}<25 \mathrm{~kg} / \mathrm{m}^{2}$.

BMI, body mass index; DM, diabetes mellitus; GDM, gestational diabetes mellitus.

BMI in each group as follows: (1) car dependent: $25.3 \mathrm{~kg} / \mathrm{m}^{2}$; (2) somewhat walkable: $25.6 \mathrm{~kg} / \mathrm{m}^{2}$; (3) very walkable: $24.6 \mathrm{~kg} / \mathrm{m}^{2}$; and (4) walker's paradise: $24.2 \mathrm{~kg} /$ $\mathrm{m}^{2}$. Despite these pregravid differences, however, gestational weight gain up to the OGTT did not differ across the groups (figure $1 \mathrm{~F}, \mathrm{p}=0.80$ ).

\section{Associations of Walk Score with metabolic outcomes in pregnancy}

We next sought to evaluate the associations of neighborhood walkability with metabolic function in pregnancy. On Spearman correlation analysis (table 2), higher Walk Score (as a continuous measure) was positively associated with pregravid total physical activity $(\mathrm{r}=0.10, \mathrm{p}=0.0003)$, non-sport leisure-time index $(\mathrm{r}=0.09, \mathrm{p}=0.001)$, and vigorous/sport index $(\mathrm{r}=0.09, \mathrm{p}=0.0007)$, and negatively correlated with pre-pregnancy BMI $(\mathrm{r}=-0.11, \mathrm{p}=0.0001)$. However, there was no association with gestational weight gain up to the OGTT. Moreover, Walk Score showed no evidence of any association with insulin sensitivity or resistance, beta-cell function or glycemia on the OGTT in pregnancy (all $|\mathrm{r}|<0.05$, p non-significant). Thus, despite its associations with pregravid physical activity and BMI, neighborhood walkability did not appear to relate to glucose homeostasis in pregnancy. Accordingly, the prevalence of GDM did not differ between the four Walk Score groups (car dependent: 21.7\%; somewhat walkable: $24.1 \%$; very walkable: $23.9 \%$; walker's paradise: $17.1 \%$; overall $\mathrm{p}=0.14$ ). Similarly, the prevalence of fasting glucose $\geq 5.1 \mathrm{mmol} / \mathrm{L}$ on the OGTT in pregnancy did not differ between the Walk Score groups (car dependent: $24.9 \%$; somewhat walkable: $13.7 \%$; very walkable: $18.5 \%$; walker's paradise: $17.8 \%$; overall $\mathrm{p}=0.28$ ) (data not shown).

We next sought to determine whether neighborhood walkability was independently associated with any of the metabolic outcomes in pregnancy, after adjustment for covariates (age, ethnicity, family history of diabetes, parity, pre-pregnancy BMI, weight gain in pregnancy up to the OGTT, and weeks' gestation at OGTT). As shown in table 3 , the four walkability groups did not differ 

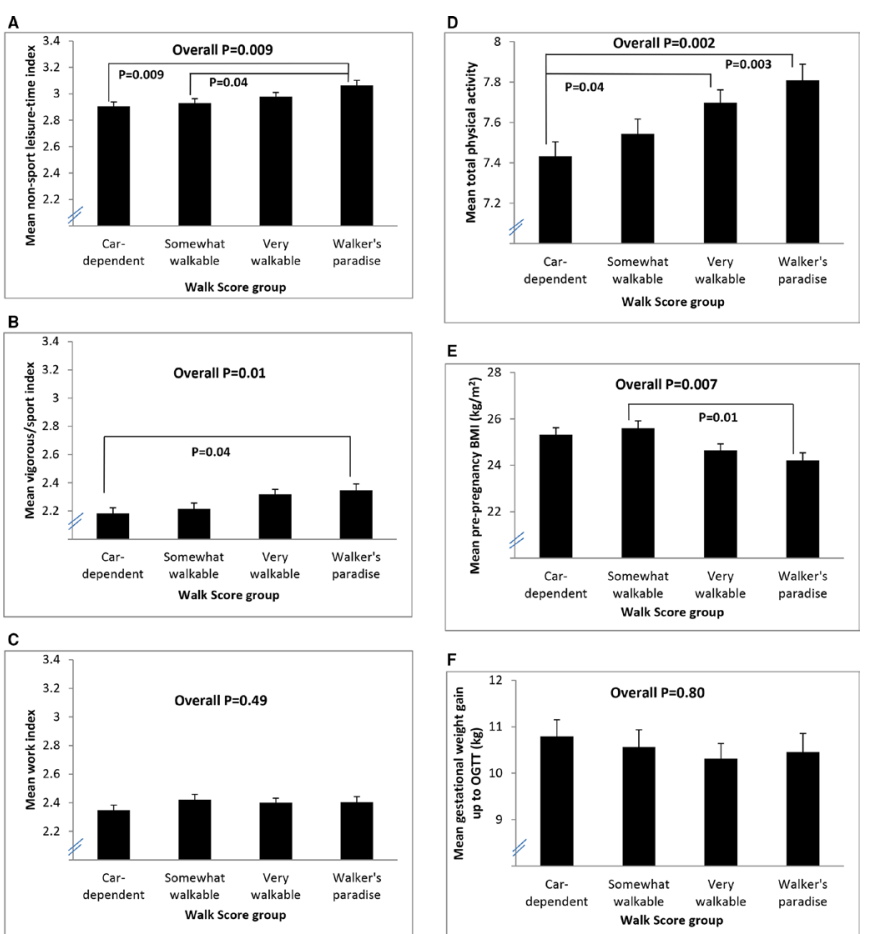

Figure 1 Plots comparing Walk Score groups with respect to (A) non-sport leisure-time index, (B) vigorous/sport index, (C) work index, (D) total physical activity, (E) pre-pregnancy body mass index (BMI), and (F) gestational weight gain up to oral glucose tolerance test (OGTT).

in mean adjusted insulin sensitivity (Matsuda index), insulin resistance (HOMA-IR), beta-cell function (ISSI-2, insulinogenic index/HOMA-IR), or glycemia (fasting glucose, $\mathrm{AUC}_{\text {glucose }}$ on the OGTT). Furthermore, these findings were unchanged on sensitivity analyses in which (1) there was further adjustment for fetal sex; (2) further adjustment for GDM in a previous pregnancy, and (3) Walk Score groups were replaced with continuous Walk Score (data not shown). In addition, these findings were unchanged on sensitivity analyses that were restricted to (1) women of white ethnicity, (2) nulliparous women, and (3) women who had no family history of diabetes (data not shown). Finally, on logistic regression analysis, Walk Score did not predict GDM (OR=1.001, 95\% CI 0.995 to 1.007 ) (table $4 \mathrm{~A}$ ). It also did not predict GDM defined by the less stringent Carpenter and Coustan criteria (OR=1.003, 95\% CI 0.998 to 1.008$)$ (table 4B).

\section{DISCUSSION}

In this study of 1318 women, we demonstrate that higher neighborhood walkability is associated with greater pregravid physical activity and lower BMI. However, in pregnancy, it did not have effects on gestational weight gain, insulin sensitivity, beta-cell function or glycemia. Accordingly, neighborhood walkability was not associated with maternal risk of GDM.

In normal human gestation, women experience a physiologic progressive decline in insulin sensitivity from 20 weeks onwards, resulting in marked insulin
Table 2 Spearman correlations of Walk Score with (1) pregravid physical activity and BMI, and with (2) metabolic function in pregnancy

\begin{tabular}{lll}
\hline & r & P value \\
\hline Pregravid & & \\
\hline Total physical activity & 0.10 & $\mathbf{0 . 0 0 0 3}$ \\
\hline Non-sport leisure-time index & 0.09 & $\mathbf{0 . 0 0 1}$ \\
\hline Vigorous/sport index & 0.09 & $\mathbf{0 . 0 0 0 7}$ \\
\hline Work index & 0.02 & 0.53 \\
\hline BMI & -0.11 & $\mathbf{0 . 0 0 0 1}$ \\
\hline In pregnancy & & \\
\hline Gestational weight gain up to the OGTT & -0.04 & 0.20 \\
\hline Insulin sensitivity/resistance & & \\
\hline Matsuda index & 0.05 & 0.09 \\
\hline HOMA-IR & -0.04 & 0.16 \\
\hline Beta-cell function & & \\
\hline ISSI-2 & -0.02 & 0.54 \\
\hline Insulinogenic index/HOMA-IR & -0.01 & 0.64 \\
\hline Glucose challenge test & -0.002 & 0.93 \\
\hline OGTT & & \\
\hline Fasting glucose & 0.02 & 0.38 \\
\hline 30 min glucose & 0.02 & 0.56 \\
\hline 1-hour glucose & 0.00006 & 0.99 \\
\hline 2-hour glucose & -0.004 & 0.88 \\
\hline 3-hour glucose & 0.006 & 0.82 \\
\hline AUC & & \\
\hline glucose & 0.0004 & 0.99 \\
\hline
\end{tabular}

Bold indicates $p \leq 0.001$.

$\mathrm{AUC}_{\text {glucose }}$, area-under-the-glucose curve; BMI, body mass index; HOMA-IR, homeostasis model assessment of insulin resistance; ISSI-2, insulin secretion-sensitivity index-2; OGTT, oral glucose tolerance test.

resistance by late pregnancy $(\sim 50 \%-70 \%$ fall in insulin sensitivity overall) ${ }^{25}$ In this setting, the maintenance of glucose homeostasis is dependent on the pancreatic betacells appropriately increasing their secretion of insulin to compensate for this degree of insulin resistance. GDM arises in a population of women in whom there exists a chronic defect in beta-cell function such that their beta-cell compensation for this challenge is insufficient (resulting in the hyperglycemia by which GDM is diagnosed). ${ }^{7}$ Thus, to lower the risk of GDM, an intervention (such as enhanced walkability) would need to reduce this marked insulin resistance to such an extent that beta-cell compensation in these at-risk women will now be sufficient to keep blood glucose levels in the non-diagnostic range. Accordingly, given the profound insulin resistance of late pregnancy, a modest improvement in insulin sensitivity per se may not lower the incidence of GDM, unless the improvement therein is of a sufficient (ie, prodigious) magnitude.

Previous studies have established Walk Score as a validated measure of neighborhood walkability that is 
Table 3 Comparison of mean adjusted metabolic outcomes in pregnancy (Matsuda index, HOMA-IR, ISSI-2, IGI /HOMA-IR, fasting glucose, $\mathrm{AUC}_{\text {glucose }}$ on OGTT) between Walk Score groups, after adjustment for the following covariates: age, ethnicity, family history of diabetes, parity, pre-pregnancy BMI, weight gain in pregnancy up to the OGTT, and weeks' gestation at OGTT

\begin{tabular}{|c|c|c|c|c|c|}
\hline & Car dependent & $\begin{array}{l}\text { Somewhat } \\
\text { walkable }\end{array}$ & Very walkable & $\begin{array}{l}\text { Walker's } \\
\text { paradise }\end{array}$ & \\
\hline & $\begin{array}{l}\text { (Walk Score } \\
<50 \text { ) }\end{array}$ & $\begin{array}{l}\text { (Walk Score } \\
50-69 \text { ) }\end{array}$ & $\begin{array}{l}\text { (Walk Score } \\
70-89 \text { ) }\end{array}$ & $\begin{array}{l}\text { (Walk Score } \\
90-100)\end{array}$ & $P$ value \\
\hline \multicolumn{6}{|c|}{ Insulin sensitivity/resistance } \\
\hline Matsuda index & $3.66 \pm 0.12$ & $3.71 \pm 0.12$ & $3.51 \pm 0.11$ & $3.83 \pm 0.14$ & 0.19 \\
\hline HOMA-IR & $1.97 \pm 0.07$ & $1.90 \pm 0.07$ & $2.07 \pm 0.07$ & $1.95 \pm 0.07$ & 0.22 \\
\hline \multicolumn{6}{|l|}{ Beta-cell function } \\
\hline ISSI-2 & $715.4 \pm 15.4$ & $731.1 \pm 16.3$ & $681.9 \pm 13.8$ & $695.0 \pm 16.3$ & 0.04 \\
\hline IGI/HOMA-IR & $9.6 \pm 0.4$ & $10.0 \pm 0.5$ & $8.8 \pm 0.4$ & $9.2 \pm 0.5$ & 0.09 \\
\hline \multicolumn{6}{|l|}{ Glycemia } \\
\hline Fasting glucose & $4.6 \pm 0.03$ & $4.6 \pm 0.03$ & $4.6 \pm 0.03$ & $4.6 \pm 0.04$ & 0.12 \\
\hline $\mathrm{AUC}_{\text {glucose }}$ & $23.14 \pm 0.24$ & $23.26 \pm 0.25$ & $23.51 \pm 0.23$ & $23.13 \pm 0.26$ & 0.53 \\
\hline
\end{tabular}

Data are presented as adjusted mean \pm SEM.

$\mathrm{AUC}_{\text {glucose}}$, area-under-the-glucose curve; BMI, body mass index; HOMA-IR, homeostasis model assessment of insulin resistance; IGI, insulinogenic index; ISSI-2, insulin secretion-sensitivity index-2; OGTT, oral glucose tolerance test.

associated with cardiometabolic risk factors (such as physical activity, obesity and blood pressure) in a variety of settings, including Toronto. ${ }^{21-24}$ In the current study, Walk Score was indeed associated with total physical activity in the year prior to pregnancy. Moreover, this relationship was driven by associations with the component domains of physical activity in the precise pattern that would be anticipated for the impact of neighborhood walkability (ie, primarily affecting non-sport leisure-time activity, with no effect on work index). Furthermore, higher neighborhood walkability was associated with lower pre-pregnancy BMI. Thus, the tracking of Walk Score with these pregravid factors was fully concordant with previous studies in non-pregnant individuals, thereby supporting the fidelity of this measure in capturing walkability in the current study. Despite these pregravid relationships, however, we show that neighborhood walkability did not have any associations with gestational weight gain or glucose homeostasis (insulin sensitivity, beta-cell function, or glycemia) in pregnancy. Indeed, besides not approaching statistical significance, the correlation coefficients between Walk Score and all of the glycemic measures were near 0 (all $\mathrm{r}<0.02$ ), suggestive of no association at all (table 2). Similarly, the estimated OR for Walk Score in predicting GDM (OR=1.001, $95 \%$ CI 0.995 to 1.007 ) was also indicative of no effect. Collectively, these data suggest that, in the face of the profound insulin resistance of pregnancy, any impact of neighborhood walkability on insulin sensitivity was too modest to have any discernible effect on glucose homeostasis in over 1300 women. As a reference for perspective, it is worth noting that the modest effect of fetal sex on maternal glucose homeostasis was readily detectable in 1074 women. $^{9}$
Our finding of an apparent discordance in the metabolic impact of walkability between the pregnant and non-pregnant states is analogous to the difference that has been observed in the relative effects of lifestyle modification on the risks of T2DM and GDM, respectively. Indeed, outside of pregnancy, a series of studies has shown that lifestyle intervention can effectively reduce the incidence of T2DM in at-risk individuals (ie, those with pre-diabetes). ${ }^{26-29}$ Conversely, studies evaluating lifestyle interventions in early pregnancy to reduce the risk of subsequent GDM have been largely unsuccessful. ${ }^{30-33}$ Moreover, a recent meta-analysis ${ }^{34}$ from a consortium of lifestyle intervention trials in pregnancy showed that lifestyle modification can reduce gestational weight gain but not lower the incidence of GDM (possibly by not sufficiently mitigating the marked insulin resistance that characterizes the latter half of gestation). These data serve to underscore the concept that there are inherent differences in the association of weight gain and insulin resistance during pregnancy as compared with the nongravid state. First, both weight gain and insulin resistance are normal physiologic features of pregnancy. Second, weight gain is not a prime determinant of insulin resistance in pregnancy (which is driven by placental hormones), in contrast to its impact in the non-gravid state. Third, the severity of normal physiologic insulin resistance in late gestation is of an overwhelming magnitude when compared with that which typically occurs with weight gain in non-pregnant individuals. When considered from this perspective, neighborhood walkability can be viewed as a non-targeted lifestyle intervention that can yield metabolic benefit prior to pregnancy but may be insufficient to markedly impact glucose homeostasis in the pregnant state. From the current data, we cannot 
Table 4 Logistic regression model of (dependent variable) GDM, with GDM defined by (A) NDDG criteria and (B) Carpenter and Coustan criteria, respectively

\begin{tabular}{|c|c|c|}
\hline Variables in model & OR & $95 \% \mathrm{Cl}$ \\
\hline \multicolumn{3}{|l|}{ A. GDM by NDDG criteria } \\
\hline Age & 1.046 & 1.012 to 1.080 \\
\hline \multicolumn{3}{|l|}{ Ethnicity } \\
\hline Asian & 1.744 & 1.180 to 2.577 \\
\hline Non-white, non-Asian & 1.336 & 0.929 to 1.922 \\
\hline Family history of DM & 1.651 & 1.203 to 2.267 \\
\hline \multicolumn{3}{|l|}{ Parity } \\
\hline 1 & 0.927 & 0.678 to 1.269 \\
\hline$>1$ & 1.004 & 0.634 to 1.589 \\
\hline Pre-pregnancy BMI & 1.049 & 1.022 to 1.078 \\
\hline Gestational weight gain up to OGTT & 1.002 & 0.978 to 1.026 \\
\hline Weeks' gestation at OGTT & 0.941 & 0.897 to 0.987 \\
\hline Walk Score & 1.001 & 0.995 to 1.007 \\
\hline \multicolumn{3}{|c|}{ B. GDM by Carpenter and Coustan criteria } \\
\hline Age & 1.042 & 1.013 to 1.072 \\
\hline \multicolumn{3}{|l|}{ Ethnicity } \\
\hline Asian & 1.523 & 1.074 to 2.160 \\
\hline Non-white, non-Asian & 1.209 & 0.877 to 1.667 \\
\hline Family history of DM & 1.519 & 1.165 to 1.980 \\
\hline \multicolumn{3}{|l|}{ Parity } \\
\hline 1 & 0.843 & 0.642 to 1.108 \\
\hline$>1$ & 1.109 & 0.740 to 1.662 \\
\hline Pre-pregnancy BMI & 1.051 & 1.026 to 1.077 \\
\hline Gestational weight gain up to OGTT & 1.000 & 0.979 to 1.021 \\
\hline Weeks' gestation at OGTT & 0.962 & 0.921 to 1.004 \\
\hline Walk Score & 1.003 & 0.998 to 1.008 \\
\hline
\end{tabular}

Reference groups are (1) white for ethnicity and (2) nulliparous for parity, respectively.

BMI, body mass index; DM, diabetes mellitus; GDM, gestational diabetes mellitus; NDDG, National Diabetes Data Group; OGTT, oral glucose tolerance test.

determine if the lack of metabolic impact in pregnancy is due to gestational changes in behavior or because of physiologic differences between the gravid and non-gravid states (eg, in the severity and determinants of insulin resistance). Either way, however, these data suggest that neighborhood walkability is not a significant determinant of glucose homeostasis in pregnancy.

Strengths of this study include the population of 1318 women reflecting a broad spectrum of neighborhood walkability (ie, $\sim 300$ women in each of the four established categories), in whom pregravid physical activity was queried prior to knowledge of the outcome of the OGTT, on which 290 were then diagnosed with GDM. Importantly, neighborhood walkability was assessed with a validated measure in relation to home address and exhibited the anticipated associations with pregravid physical activity. Moreover, all of the women underwent systematic assessment of insulin sensitivity/resistance and beta-cell function, thereby providing pathophysiologic insight into how walkability might affect the risk of GDM. Conversely, a limitation of this study is that the observational design precludes definitive ascertainment of causality in observed associations. Additional limitations are the absence of data on pre-pregnancy clinical risk factors of previous impaired fasting glucose or Alc $>5.7 \%$ and pre-pregnancy measurements of insulin sensitivity/resistance and beta-cell function. The absence of a measurement of physical activity in pregnancy is also a limitation. Lastly, the absence of an effect of walkability on risk of GDM defined by NDDG criteria does not rule out an impact on GDM defined by less stringent criteria such as those of the International Association of Diabetes in Pregnancy Study Groups (although tables 2 and 3 show no association of Walk Score with continuous measures of glycemia and Walk Score did not predict GDM by Carpenter and Coustan criteria in table 4B).

It should be recognized that our data do not rule out any impact of walkability on risk of GDM (however small), particularly since neighborhood design will affect the entire population where even a modest effect can be beneficial for society. Accordingly, these data certainly do not argue against city planning as a societal approach to the T2DM epidemic (as enhanced walkability has been linked to cardiometabolic benefits outside of pregnancy). ${ }^{2-521-24}$ However, our inability to detect any discernible impact of neighborhood walkability on insulin sensitivity, beta-cell function and glycemia in 1318 pregnant women suggests that the overall effect of urban design on the incidence of GDM may be relatively modest (as compared with its benefits outside of pregnancy). That said, in women who develop GDM, one would anticipate that enhanced neighborhood walkability should still be beneficial in reducing their risk of progression to T2DM in the years after their pregnancy (as weight control is a key modifiable determinant of this risk). ${ }^{7}$

In conclusion, neighborhood walkability is associated with greater physical activity and lower BMI prior to pregnancy but does not have a discernible impact on antepartum weight gain or glucose homeostasis when the same women become pregnant. Accordingly, neighborhood walkability is not a significant determinant of maternal risk of GDM. Taken together, these findings do not argue against urban planning as a means of promoting healthy lifestyle practices and reducing the risk of T2DM in the overall population. Rather, these data suggest that the effect of neighborhood design on the risk of GDM will be comparatively modest, likely reflecting the intrinsic physiologic differences between the gravid and non-gravid states.

Acknowledgements BZ is the Stephen and Suzie Pustil Diabetes Research Scientist at Mount Sinai Hospital. RR holds the Boehringer Ingelheim Chair in Beta-cell Preservation, Function and Regeneration at Mount Sinai Hospital and his research program is supported by the Sun Life Financial Program to Prevent Diabetes in Women. 
Contributors RR, AJH, MS, and BZ designed and implemented the study. SK, SM, $\mathrm{CY}$ and RR contributed to data collection and analysis. CY performed the statistical analyses. SK wrote the first draft. All authors critically revised the manuscript for important intellectual content. All authors approved the final manuscript.

Funding This work was supported by the Canadian Institutes of Health Research (ClHR; MOP-84206 and PJT-156286) and Diabetes Canada (CDA-0G-3-15-4924-RR).

Competing interests None declared.

Patient consent for publication Not required.

Ethics approval The study protocol has been approved by the Mount Sinai Hospital Research Ethics Board and all participants have provided written informed consent.

Provenance and peer review Not commissioned; externally peer reviewed.

Data availability statement Data are available upon reasonable request to the corresponding author and upon institutional approval.

Open access This is an open access article distributed in accordance with the Creative Commons Attribution Non Commercial (CC BY-NC 4.0) license, which permits others to distribute, remix, adapt, build upon this work non-commercially, and license their derivative works on different terms, provided the original work is properly cited, appropriate credit is given, any changes made indicated, and the use is non-commercial. See: http://creativecommons.org/licenses/by-nc/4.0/.

ORCID iDs

Anthony J Hanley http://orcid.org/0000-0002-6364-2444

Ravi Retnakaran http://orcid.org/0000-0003-1989-027X

\section{REFERENCES}

1 International Diabetes Federation. IDF diabetes atlas, 8th ED. Brussels, Belgium: international diabetes Federation, 2017. Available: http://www.diabetesatlas.org

2 Sallis JF, Floyd MF, Rodríguez DA, et al. Role of built environments in physical activity, obesity, and cardiovascular disease. Circulation 2012;125:729-37.

3 Booth GL, Creatore MI, Moineddin R, et al. Unwalkable neighborhoods, poverty, and the risk of diabetes among recent immigrants to Canada compared with long-term residents. Diabetes Care 2013;36:302-8.

4 Christine PJ, Auchincloss AH, Bertoni AG, et al. Longitudinal associations between neighborhood physical and social environments and incident type 2 diabetes mellitus: the multiethnic study of atherosclerosis (MESA). JAMA Intern Med 2015; 175:1311-20.

5 Creatore Ml, Glazier RH, Moineddin R, et al. Association of neighborhood walkability with change in overweight, obesity, and diabetes. JAMA 2016;315:2211-20.

6 Gluckman PD, Hanson MA, Cooper C, et al. Effect of in utero and early-life conditions on adult health and disease. N Engl J Med 2008;359:61-73.

7 Buchanan TA, Xiang AH, Page KA. Gestational diabetes mellitus: risks and management during and after pregnancy. Nat Rev Endocrinol 2012;8:639-49.

8 Retnakaran R, Wen SW, Tan H, et al. Association of timing of weight gain in pregnancy with infant birth weight. JAMA Pediatr 2018;172:136-42.

9 Retnakaran R, Kramer CK, Ye C, et al. Fetal sex and maternal risk of gestational diabetes mellitus: the impact of having a Boy. Diabetes Care 2015;38:844-51.

10 Baecke JA, Burema J, Frijters JER. A short questionnaire for the measurement of habitual physical activity in epidemiological studies. Am J Clin Nutr 1982;36:936-42.

11 Pereira MA, FitzerGerald SJ, Gregg EW, et al. A collection of physical activity questionnaires for health-related research. Med Sci Sports Exerc 1997;29:S1-205.

12 Ainsworth BE, Haskell WL, Whitt MC, et al. Compendium of physical activities: an update of activity codes and Met intensities. Med Sci Sports Exerc 2000;32:S498-516.
13 National Diabetes Data Group. Classification and diagnosis of diabetes mellitus and other categories of glucose intolerance. Diabetes 1979;28:1039-57.

14 Matsuda M, DeFronzo RA. Insulin sensitivity indices obtained from oral glucose tolerance testing: comparison with the euglycemic insulin clamp. Diabetes Care 1999;22:1462-70.

15 Matthews DR, Hosker JP, Rudenski AS, et al. Homeostasis model assessment: insulin resistance and ?-cell function from fasting plasma glucose and insulin concentrations in man. Diabetologia 1985;28:412-9.

16 Retnakaran R, Shen S, Hanley AJ, et al. Hyperbolic relationship between insulin secretion and sensitivity on oral glucose tolerance test. Obesity 2008;16:1901-7.

17 Retnakaran R, Qi Y, Goran Ml, et al. Evaluation of proposed oral disposition index measures in relation to the actual disposition index. Diabet Med 2009;26:1198-203.

18 Duncan DT, Aldstadt J, Whalen J, et al. Validation of walk Score $\AA$ for estimating neighborhood Walkability: an analysis of four us metropolitan areas. Int J Environ Res Public Health 2011;8:4160-79.

19 Carr LJ, Dunsiger SI, Marcus BH. Walk Score ${ }^{\mathrm{TM}}$ as a global estimate of neighborhood Walkability. Am J Prev Med 2010;39:460-3.

20 Carr LJ, Dunsiger SI, Marcus BH. Validation of walk score for estimating access to walkable amenities. Br J Sports Med 2011;45:1144-8.

21 Chiu M, Shah BR, Maclagan LC, et al. Walk Score ${ }^{\circledR}$ and the prevalence of utilitarian walking and obesity among Ontario adults: a cross-sectional study. Health Rep 2015;26:3-10.

22 Loo CKJ, Greiver M, Aliarzadeh B, et al. Association between neighbourhood walkability and metabolic risk factors influenced by physical activity: a cross-sectional study of adults in Toronto, Canada. BMJ Open 2017;7:e013889.

23 Méline J, Chaix B, Pannier B, et al. Neighborhood walk score and selected cardiometabolic factors in the French record cohort study. BMC Public Health 2017;17:960.

24 Hirsch JA, Moore KA, Evenson KR, et al. Walk Score $\AA$ and transit Score ${ }^{8}$ and walking in the multi-ethnic study of atherosclerosis. Am $J$ Prev Med 2013;45:158-66.

25 Kühl C. Etiology and pathogenesis of gestational diabetes. Diabetes Care 1998;21:B19-26.

26 Knowler WC, Barrett-Connor E, Fowler SE, et al. Diabetes prevention program Research Group. reduction in the incidence of type 2 diabetes with lifestyle intervention or metformin. N Engl J Med 2002;346:393-403.

27 Pan XR, Li GW, Hu YH, et al. Effects of diet and exercise in preventing NIDDM in people with impaired glucose tolerance. The dA Qing IGT and diabetes study. Diabetes Care 1997;20:537-44.

28 Tuomilehto J, Lindström J, Eriksson JG, et al. Finnish diabetes prevention Study Group. prevention of type 2 diabetes mellitus by changes in lifestyle among subjects with impaired glucose tolerance. N Engl J Med 2001;344:1343-50.

29 Ramachandran A, Snehalatha C, Mary S, et al. The Indian diabetes prevention programme shows that lifestyle modification and metformin prevent type 2 diabetes in Asian Indian subjects with impaired glucose tolerance (IDPP-1). Diabetologia 2006;49:289-97.

30 Dodd JM, Turnbull D, McPhee AJ, et al. Antenatal lifestyle advice for women who are overweight or obese: limit randomised trial. BMJ 2014;348:g1285.

31 Poston L, Bell R, Croker $\mathrm{H}$, et al. Effect of a behavioural intervention in obese pregnant women (the upbeat study): a multicentre, randomised controlled trial. Lancet Diabetes Endocrinol 2015;3:767-77.

32 Simmons D, Devlieger R, van Assche A, et al. Effect of physical activity and/or healthy eating on GDM risk: the DALI lifestyle study. $J$ Clin Endocrinol Metab 2017;102:903-13.

33 Vinter CA, Jensen DM, Ovesen P, et al. The lip (lifestyle in pregnancy) study: a randomized controlled trial of lifestyle intervention in 360 obese pregnant women. Diabetes Care 2011;34:2502-7.

34 Peaceman AM, Clifton RG, Phelan S, et al. Lifestyle interventions limit gestational weight gain in women with overweight or obesity: LIFE-Moms prospective Meta-Analysis. Obesity 2018;26:1396-404. 